Brit. J. industr. Med., 1965, 22, 295.

\title{
VENTILATORY CAPACITY CHANGES ON EXPOSURE TO COTTON DUST AND THEIR RELEVANCE TO BYSSINOSIS IN AUSTRALIA
}

\author{
BY \\ BRYAN GANDEVIA and JAMES MILNE \\ From the Thoracic Division, University Department of Medicine, Prince Henry Hospital, \\ Little Bay, Sydney, Australia
}

(RECEIVED FOR PUBLICATION FEBRUARY 15, 1965)

\begin{abstract}
The same plan of investigation as was used in a previous study of jute workers (Gandevia and Milne, 1965) has been applied to a survey of 50 workers in the blowroom and carding and spinning area of a Sydney cotton mill. Significant decreases in ventilatory capacity were recorded on Friday, Monday, and the following Thursday, with, on the average, complete 'overnight' recovery, as indicated by similar morning values. Slightly, but not significantly, greater differences were observed in seven subjects with mild byssinotic symptoms and in five subjects with an observed productive cough on request. No effect of sex, shift, or history of cough and sputum was demonstrable. By contrast with the jute workers, no influence of smoking habit was apparent. The larger decreases in ventilatory capacity were observed in those with the higher F.E.V.1.0 :F.V.C. ratios, whereas the reverse trend was noted in the jute workers. The occurrence of significant large decreases in those employed in the industry for less than a month, in conjunction with other evidence, suggests that a factor of 'self-selection' may be operative among cotton employees in this country and may be related to the apparently low prevalence of clinically important byssinosis. Attention is drawn to two different patterns of change of ventilatory capacity over a week in subjects exposed to dusts sometimes associated with symptoms of byssinosis; the relationship of these changes and of chronic bronchitis to the development of clinical byssinosis is discussed.
\end{abstract}

Studies of symptoms and ventilatory capacity in workers exposed to cotton dust have been reported from England, Holland, Africa, Egypt, India, and the United States (Leading Article, 1962). Until the comparatively recent development (Schilling, 1956) of this international interest, byssinosis was considered uncommon in some of these countries, and, in fact, this is the position in Australia. Enquiry over several years of industrial and thoracic physicians aware of byssinosis indicates that it is not regarded as a significant problem, and neither management nor trade unions appear to have felt concern. This paper records the results of a preliminary study of a selected area of one cotton mill in Sydney and relates chiefly to the changes in ventilatory capacity observed over a shift and over a working week. The results establish the 'biological activity' of the dust under Australian conditions. Certain factors which may influence the pattern of reaction to inhaled dusts are examined, and consideration of these leads to the suggestion that a process of selection may be operative in Australian cotton mill employees; this may in turn be related to the probably low prevalence of advanced byssinosis.

\section{The Mill and The Plan of Investigation}

According to personnel with experience of the cotton industry in both Britain and Australia, the processes involved in the production of yarn* from raw cotton were similar, as were the general working and environmental conditions, in the mills chiefly developed in the last 40 years.

In the mill studied, raw cotton was obtained from various countries, including North and South

\footnotetext{
* Of counts below 20 in this mill.
} 
America and Australia. Two nearby areas, including the dustiest parts of the mill, were selected for investigation: the blowroom and another large room, about half of which was devoted to carding and the other half to spinning preparation (draw frames and speed frames). The blowroom processes, with the exception of the actual bale-breaking, were largely enclosed and exhausted, so that this room was relatively free of visible airborne dust. The main room, of approximately $430,000 \mathrm{cu}$. ft., housed 63 carding machines (over 30 years old), draw frames, and speed frames (about 10 years old). There was no local exhaust ventilation in relation to the machinery, but conventional air-conditioning and filtration provided about five changes of air per hour, although permitting some recirculation. Again, experienced operatives, as well as one of the authors, considered that the working conditions in all areas were certainly no less dusty than in comparable British mills. A process such as stripping, for example, was carried out once daily in precisely the same way, with no special precautions, as was demonstrated to one of us in a Lancashire mill some years ago; vacuum stripping was used three times a day.

Personnel and Procedure.-All 50 employees, including 15 women, in the selected area took part in the investigation. Both the day (approximately 7.00 a.m. to 3.00 p.m.) and evening (approximately 3.00 p.m. to 11.00 p.m.) shifts were studied; all employees always worked on the same shift. Seven men in the two shifts were constantly employed in the blowroom, about 16 men in the carding section (by eye the dustiest work), and about 16 subjects, mostly women, on draw frames and speed frames. The 11 men comprising the remainder of the series of 50 employees were employed in unskilled work or as foremen and instructors.

After a 'practice blow' for most of the employees (watched by the remainder) on Thursday, all personnel were tested before and at the end of their respective shifts on the Friday and on the following Monday. Normal work at the mill was continued on Saturday but the mill did not operate on Sunday. For simplicity in presenting the detailed results, the chronological sequence is inverted so that Monday is regarded as the first day of the study. The tests were also repeated towards the end of each shift on the following Thursday, thus providing virtually a duplicate set of results for changes over an entire working week. Since these were found to be no different from the analogous data for the previous Friday, of which they are thus confirmatory, we shall not discuss them further in detail. However, on this occasion isoprenaline sulphate $1 \%$ was administered from a Wright nebulizer for one and a half minutes to 15 Englishspeaking men, to whom the procedure could be easily explained; the ventilatory tests were then repeated within the next five minutes.

The ventilatory capacity tests (J.M.) were performed in a remote corner of the spinning section of the main room, with the subject seated. The forced expiratory volume at one second (F.E.V.1.0 $)$ and the forced vital capacity (F.V.C.) were read directly off the scale of a Godart pulmometer; the highest value was recorded from three attempts in which the F.E.V.1.0 values agreed within $5 \%$. The forced expiratory ratio (F.E.R.) (F.E.V.1.0/V.C.) was subsequently calculated. Testing began before the shift commenced but was not completed until the shift had been in progress for about half an hour, so that minor dust exposure had already occurred in some subjects. The volumes were not corrected for temperature; the temperature range for the entire series of observations was $21^{\circ}$ to $24^{\circ} \mathrm{C}$., the temperatures on Monday being about one degree higher than on Friday. Weather conditions were fine and mild, with no gross fluctuations in air pollution.

All personnel were interviewed (B.G.), and the British Medical Research Council's short questionnaire on respiratory symptoms, with some deletions and additions, was completed. The total duration of employment in cotton mills (some employees had previously worked in mills in England and on the continent) was recorded. Employees were finally asked 'Does the dust worry you at all?' and, if the response was in the negative, 'Does it affect your chest?' If the reply was positive, all symptoms volunteered were recorded, and the second question was asked if respiratory symptoms were not mentioned. Details of respiratory symptoms on exposure were sought, and, if not mentioned, enquiry was made regarding cough, sputum, wheeze, dyspnoea, and the days of the week on which symptoms were noticed. Before any history was taken, on two days, the subject was asked to take a big breath and cough into a container; this cough was recorded as 'productive' or positive if, on either day, the cough was 'loose', as judged by ear, whether or not any actual specimen of sputum was produced for inspection.

All but two subjects with mild (grade 2) 'shortness of breath' gave a history of normal exercise tolerance. One person, employed in the cotton industry for 15 years, had had asthma for about 20 years, and one had had recurrent bronchitis; both had been absent from work once or twice a year but both denied any symptoms related to dust exposure. All personnel had had normal chest radiographs on mass radiography during the previous two years.

The sex, average age, and average duration of employment in the cotton industry of subjects in each shift are set out in Table 1 .

Lapses.-As there were 50 employees available for study, 200 estimations of ventilatory capacity should have been made over the two main days of the survey. In fact, only 190 , an overall lapse rate of $5 \%$ and involving seven subjects, were recorded. One 'end of shift' observation was lost on three subjects; two, we believe, were anxious to avoid the tests (one showed a decrease in F.E.V.1.0 $870 \mathrm{ml}$. on the previous day, and one, the only defaulter admitting to symptoms but showing no change in F.E.V.1.0 on Friday, was always a reluctant attender and could not be located). Two employees resigned, accounting for the loss of four observations. A 
TABLE 1

AGE, SEX, AND YEARS IN COTTON INDUSTRY IN RELATION TO SHIFT

\begin{tabular}{l|c|c|c}
\hline \multicolumn{1}{c|}{ Shift } & $\mathrm{n}$ & Mean Age & $\begin{array}{c}\text { Years in Cotton } \\
\text { Industry }\end{array}$ \\
\hline $\begin{array}{l}\text { Morning } \\
\text { Males } \\
\text { Females }\end{array}$ & 17 & $\begin{array}{c}33 \cdot 2(19-52) \\
9\end{array}$ & $\begin{array}{l}10 \cdot 3(38-63) \\
17 \cdot 1(2-29)\end{array}$ \\
\hline Mean & & $37 \cdot 0$ & $12 \cdot 2$ \\
\hline $\begin{array}{l}\text { Afternoon } \\
\text { Males }\end{array}$ & 18 & $34 \cdot 1(21-55)$ & $6.5(<1-28)$ \\
Females & 6 & $39 \cdot 3(29-60)$ & $7 \cdot 9(<1-30)$ \\
\hline Mean & & $35 \cdot 4$ & 6.8 \\
\hline
\end{tabular}

Means in years; ranges in parentheses

'beginning-of-shift' observation was omitted in one subject, whose failure to appear was inadvertently overlooked at the time; locating him for the 'end-of-shift' test proved difficult. This person, who had shown a decrease in F.E.V.1.0 $440 \mathrm{ml}$. on the previous day, resigned during the next week. One subject, noted above as having asthma, viewed the 'practice blow' with some apprehension and was absent on the next day (Friday); on Monday morning the initial ventilatory tests showed evidence of airways obstruction with a further decrease in F.E.V.1.0 $620 \mathrm{ml}$. over the shift. There is therefore some evidence to suggest that the 'losses' were not random and that they occurred in employees who were more susceptible than the average in terms of ventilatory capacity changes. Wherever feasible the statistical analysis includes the maximum number of subjects and observations, that is, the loss of an isolated observation or a day's observations has not led to the complete exclusion of that subject from the analysis. That their inclusion or exclusion in fact makes little difference can be seen from Table 2, where the mean F.E.V.1.0 and F.V.C. values are shown with and without these subjects.

\section{Table Symbols}

In the tables supplementing the text, the symbols $A$ and $B$ are allotted to the ventilatory capacity measurements at the beginning and the end, respectively, of Monday's shifts, and the symbols C and D to the estimations at the beginning and end of
Friday's shifts. In the text, reference is made to the number of the table followed by the number given to the appropriate line of the table. The term 'significant' implies $\mathbf{P}<0.05$.

\section{Results}

Table 2 shows the mean F.E.V.1.0 and F.V.C. results for men and women for both shifts together (a) when all the available observations are included and $(b)$ when analysis is confined to those for whom the series of four observations is complete. The detailed analysis below is based on differences between paired observations rather than on the absolute values.

Overall Results.-Analysis of the data for the entire series (Table 3), a procedure validated below as regards grouping of the sexes and shifts, reveals a highly significant mean decrease in F.E.V.1.0 over both working days $(150 \mathrm{ml}$. on Monday and $128 \mathrm{ml}$.

TABLE 3

MEAN CHANGES IN F.E.V.1.0 ON EXPOSURE (LITRES): WHOLE SERIES

\begin{tabular}{l|c|c|c|c|c}
\hline & $\overline{\mathrm{x}}$ & $\mathrm{n}$ & $\mathrm{s}$ & $\mathrm{t}$ & \multicolumn{1}{|c}{ P } \\
\hline 1. A - B & -0.150 & 45 & 0.212 & 4.67 & $<0.001$ \\
2. C - D & -0.128 & 48 & 0.234 & 3.79 & $<0.001$ \\
3. A - C & +0.022 & 46 & 0.199 & 0.08 & $<0.95>0.90$ \\
4. A - D & -0.108 & 47 & 0.204 & 3.63 & $<0.001$ \\
\hline
\end{tabular}

A: Monday, commencement of shift.

B: Monday, end of shift.

C: Friday, commencement of shift.

D: Friday, end of shift.

A - B, C - D, etc. imply the difference between estimations at these times. The same notation is employed in subsequent tables.

on Friday) (Table 3.1, 3.2) and a similar significant decrease over the entire working week (Table 3.4). Mention may be made again of the fact that a comparable and significant mean decrease of $150 \mathrm{ml}$. was observed over a further week when the tests were repeated on the following Thursday. No significant change in F.E.V.1.0 was found between the initial

TABLE 2

MEAN VALUES FOR F.E.V.1.0 AND F.V.C. (LITRES AND STANDARD DEVIATIONS) FOR THE WHOLE SERIES AND AFTER EXCLUDING DEFAULTERS

\begin{tabular}{|c|c|c|c|c|c|c|c|c|c|c|c|c|c|c|c|c|}
\hline & \multicolumn{4}{|c|}{$\mathbf{A}$} & \multicolumn{4}{|c|}{ B } & \multicolumn{4}{|c|}{ C } & \multicolumn{4}{|c|}{ D } \\
\hline & \multicolumn{2}{|c|}{ F.E.V. ${ }_{1 \cdot 0}$} & \multicolumn{2}{|c|}{ F.V.C. } & \multicolumn{2}{|c|}{ F.E.V.:1.0 } & \multicolumn{2}{|c|}{ F.V.C. } & \multicolumn{2}{|c|}{ F.E.V.1.0 } & \multicolumn{2}{|c|}{ F.V.C. } & \multicolumn{2}{|c|}{ F.E.V.:1.0 } & \multicolumn{2}{|c|}{ F.V.C. } \\
\hline & $\overline{\mathbf{x}}$ & $\mathbf{s}$ & $\bar{x}$ & $\mathbf{s}$ & $\overline{\mathbf{x}}$ & $\mathbf{s}$ & $\overline{\mathbf{x}}$ & $\mathbf{s}$ & $\overline{\mathbf{x}}$ & $\mathbf{s}$ & $\overline{\mathbf{x}}$ & $\mathbf{s}$ & $\overline{\mathbf{x}}$ & $\mathbf{s}$ & $\overline{\mathbf{x}}$ & $\mathbf{s}$ \\
\hline Whole series & $\begin{array}{l}3.00 \\
\mathrm{n}=\end{array}$ & $\begin{array}{c}0.82 \\
48\end{array}$ & $3 \cdot 76$ & 0.93 & $\stackrel{2 \cdot 87}{\mathrm{n}}=$ & $\begin{array}{l}0.82 \\
45\end{array}$ & 3.69 & 0.98 & $\mathrm{n}^{3.02}=$ & $\begin{array}{l}0.78 \\
48\end{array}$ & $3 \cdot 73$ & 0.87 & $\stackrel{2.92}{=}$ & $\begin{array}{l}0.81 \\
49\end{array}$ & $3 \cdot 73$ & 0.92 \\
\hline $\begin{array}{l}\text { Whole series } \\
\text { less defaulters }\end{array}$ & $\mathrm{n}^{3.02}=$ & $\begin{array}{c}0.83 \\
43\end{array}$ & $3 \cdot 76$ & 1.02 & $\mathrm{n}=$ & $\begin{array}{l}0.81 \\
43\end{array}$ & 3.66 & 0.82 & $\mathrm{n}^{3.02}=$ & $\begin{array}{l}0.81 \\
43\end{array}$ & $3 \cdot 74$ & 0.91 & $\stackrel{2.90}{=}$ & $\begin{array}{l}0.83 \\
43\end{array}$ & $3 \cdot 70$ & 0.93 \\
\hline
\end{tabular}

$A=$ Monday, commencement of shift $\mathbf{B}=$ Monday, end of shift; $C=$ Friday, commencement of shift; $D=$ Friday, end of shift. 
values on Monday and on Friday (Table 3.3) implying, presumably, overnight recovery of ventilatory capacity. There was no tendency for those showing decreases greater than the mean decrease for the series on Monday to suffer larger reductions than the remainder between Monday and Friday mornings.

Influence of Shift and Sex.-Individually significant mean decreases in F.E.V.$_{1 \cdot 0}$ of the order of 120 to $170 \mathrm{ml}$. were found during Monday and Friday for both shifts (Table 4.1, 4.2, 4.3), the decrease for the morning shift being greater on Monday and for the afternoon shift on Friday, but comparison reveals no significant differences between these means. The

TABLE 4

MEAN CHANGES IN F.E.V.1.• (LITRES) ACCORDING TO SHIFT

\begin{tabular}{|c|c|c|c|c|c|}
\hline & $\overline{\mathbf{x}}$ & $\mathbf{n}$ & $\mathbf{s}$ & $\mathbf{t}$ & $\mathbf{P}$ \\
\hline $\begin{array}{l}\text { Morning shift } \\
\text { 1. A - B } \\
\text { 2. C - D }\end{array}$ & $\begin{array}{l}-0.171 \\
-0.121\end{array}$ & $\begin{array}{l}24 \\
25\end{array}$ & $\begin{array}{l}0.220 \\
0 \cdot 231\end{array}$ & $\begin{array}{l}3 \cdot 81 \\
2 \cdot 62\end{array}$ & $\begin{array}{l}<0.001 \\
<0.02>0.01\end{array}$ \\
\hline $\begin{array}{l}\text { Afternoon shift } \\
\text { 3. A - B } \\
\text { 4. C-D }\end{array}$ & $\begin{array}{l}-0.125 \\
-0.134\end{array}$ & $\begin{array}{l}21 \\
23\end{array}$ & $\begin{array}{l}0.205 \\
0.241\end{array}$ & $\begin{array}{l}2 \cdot 79 \\
2 \cdot 67\end{array}$ & $\begin{array}{l}<0.02>0.01 \\
<0.02>0.01\end{array}$ \\
\hline
\end{tabular}

change observed between the initial ('pre-work') test on Monday and the final ('after-work') test on Friday is also of the same order of magnitude for both shifts (about $100 \mathrm{ml}$.), and for both shifts the mean change between the initial values for Monday and Friday does not differ significantly from zero.

Comparison between the sexes (Table 5), both of which show significant falls in F.E.V.1.0 days, reveals higher mean decreases in F.E.V.1.0 for women than for men for both Monday and Friday work periods (Table 5.1, 5.2, 5.3, 5.4), but these differences do not reach significance (Table 5.5, 5.6). The mean decrease for the women tends to be slightly higher for the afternoon shift but again the difference is not significant. The results for the women also conform to the general pattern in

TABLE 5

MEAN CHANGES IN F.E.V.1.॰ ACCORDING TO SEX

\begin{tabular}{|c|c|c|c|c|c|}
\hline & $\overline{\mathbf{x}}$ & $\mathbf{n}$ & $\mathbf{s}$ & $t$ & $\mathbf{P}$ \\
\hline $\begin{array}{l}\text { Male } \\
\text { 1. } \\
\text { 2. } \\
\mathbf{C}\end{array}$ & $\begin{array}{l}-0.132 \\
-0.089\end{array}$ & $\begin{array}{l}31 \\
34\end{array}$ & $\begin{array}{l}0.209 \\
0.208\end{array}$ & $\begin{array}{l}3.52 \\
2 \cdot 49\end{array}$ & $\begin{array}{l}<0.005>0.001 \\
<0.02>0.01\end{array}$ \\
\hline $\begin{array}{r}\text { Female } \\
\text { 3. } \mathrm{A}=\mathrm{B} \\
\text { 4. } \mathrm{C}=\mathrm{D}\end{array}$ & $\begin{array}{l}-0.181 \\
-0.222\end{array}$ & $\begin{array}{l}14 \\
14\end{array}$ & $\begin{array}{l}0.227 \\
0.273\end{array}$ & $\begin{array}{l}3.98 \\
3.04\end{array}$ & $\begin{array}{l}<0.02>0.01 \\
<0.01>0.005\end{array}$ \\
\hline $\begin{array}{l}\text { 5. Comparison of } \\
1 \text { and } 3 \\
\text { 6. Comparison of } \\
2 \text { and } 4\end{array}$ & & $\begin{array}{l}45 \\
48\end{array}$ & 0.228 & 1.83 & $\begin{array}{c}\text { n.s. } \\
<0.10>0.05\end{array}$ \\
\hline
\end{tabular}

showing no difference in the initial values for Monday and for Friday.

Although we do not wish to argue the validity or otherwise of the procedure, taking the mean change for each subject over both days of observation has the effect of reducing the scatter; when this is done there is still no significant difference in the behaviour of the two sexes or the two shifts.

In the present study there is therefore no significant influence of sex or of shift on the findings, and for further consideration of changes in ventilatory capacity the data are pooled.

Influence of Process.-Significant mean decreases in F.E.V..$_{1.0}$ are found in those considered to have 'mild' or 'moderate' dust exposure, as judged by eye (Table 6.1, 6.2, 6.4, 6.5), but there was no significant difference between the decreases observed in the two groups. No change in the initial 'pre-work' values

TABLE 6

MEAN CHANGES IN F.E.V.1.0 ACCORDING TO PROCESS (see text)

\begin{tabular}{|c|c|c|c|c|c|}
\hline & $\overline{\mathbf{x}}$ & $\mathbf{n}$ & s & $t$ & $\mathbf{P}$ \\
\hline $\begin{array}{l}\text { A - B } \\
\text { 1. Moderate } \\
\text { exposure } \\
\text { 2. Mild exposure } \\
\text { 3. Comparison of } \\
1 \text { and } 2\end{array}$ & $\begin{array}{l}-0.178 \\
-0.139\end{array}$ & $\begin{array}{l}12 \\
33 \\
45\end{array}$ & $\begin{array}{l}0 \cdot 147 \\
0 \cdot 240 \\
0 \cdot 213\end{array}$ & $\begin{array}{l}4 \cdot 19 \\
3 \cdot 32 \\
0 \cdot 54\end{array}$ & $\begin{array}{l}<0.005>0.001 \\
<0.005>0.001 \\
<0.60>0.50\end{array}$ \\
\hline $\begin{array}{l}\mathrm{C}-\mathrm{D} \\
\text { 4. Moderate } \\
\text { exposure } \\
\text { 5. Mild exposure } \\
\text { 6. Comparison of } \\
4 \text { and } 5\end{array}$ & $\begin{array}{l}-0.083 \\
-0.145\end{array}$ & $\begin{array}{l}12 \\
36 \\
48\end{array}$ & $\begin{array}{l}0.122 \\
0.255 \\
0.230\end{array}$ & $\begin{array}{l}2.35 \\
3.41 \\
0.81\end{array}$ & $\begin{array}{l}<0.05>0.025 \\
<0.005>0.001 \\
<0.50>0.40\end{array}$ \\
\hline
\end{tabular}

was apparent in either group. Separation of the subjects employed on carding, which appeared to be the dustiest process, and a comparison with other workers also failed to reveal any significant effect of the process. In the absence of dust counts, no special importance is attached to this finding.

Influence of Smoking.-No significant difference was found between the mean decrease in F.E.V.1.0 observed on Monday or Friday for smokers and non-smokers, both groups showing a significant mean decrease of between 113 and $176 \mathrm{ml}$. (Table 7.1, $7.2,7.6,7.7)$; comparison shows no significant difference in behaviour (Table 7.3, 7.8). Only one of the 15 women smoked, whereas 20 of the 35 men did so; exclusion of the women does not alter the conclusions or the order of magnitude of the difference (Table 7.4, 7.5). The difference in F.E.V.1.0 between the initial values on Monday and on Friday does not differ significantly from zero in either 
TABLE 7

MEAN CHANGES IN F.E.V. .1.0 ACCORDING TO SMOKING HABIT

\begin{tabular}{|c|c|c|c|c|c|}
\hline & $\overline{\mathbf{x}}$ & $\mathbf{n}$ & $\mathbf{s}$ & $\mathbf{t}$ & $\mathbf{P}$ \\
\hline $\begin{array}{l}\text { A - B } \\
\text { 1. Smokers } \\
\text { 2. Non-smokers } \\
\text { 3. Comparison of } \\
\text { 1 and } 2 \\
\text { 4. Males only } \\
\text { smokers } \\
\text { 5. Males only } \\
\text { non-smokers }\end{array}$ & $\begin{array}{l}-0.176 \\
-0.132 \\
-0.144 \\
-0.124\end{array}$ & $\begin{array}{l}18 \\
27 \\
45 \\
17 \\
14\end{array}$ & $\begin{array}{l}0.192 \\
0.227 \\
0.214 \\
0.197 \\
0.164\end{array}$ & $\begin{array}{l}3.89 \\
3.02 \\
0.67 \\
3.01 \\
2.83\end{array}$ & $\begin{array}{l}<0.005>0.001 \\
<0.01>0.005 \\
<0.60>0.50 \\
<0.01>0.005 \\
<0.02>0.01\end{array}$ \\
\hline $\begin{array}{l}\text { C - D } \\
\text { 6. Smokers } \\
\text { 7. Non-smokers } \\
\text { 8. Comparison of } \\
6 \text { and } 7\end{array}$ & $\begin{array}{l}-0.113 \\
-0.139\end{array}$ & $\begin{array}{l}21 \\
27 \\
48\end{array}$ & $\begin{array}{l}0.197 \\
0.260\end{array}$ & $\begin{array}{l}2 \cdot 63 \\
2 \cdot 78\end{array}$ & $\begin{array}{c}<0.02>0.01 \\
<0.01>0.005 \\
\text { n.s. }\end{array}$ \\
\hline $\begin{array}{l}A-\text { C } \\
\text { 9. Smokers } \\
\text { 10. Non-smokers }\end{array}$ & $\begin{array}{r}-0.014 \\
+0.047\end{array}$ & $\begin{array}{l}20 \\
26\end{array}$ & & & $\begin{array}{l}\text { n.s. } \\
\text { n.s. }\end{array}$ \\
\hline
\end{tabular}

group (Table 7.9, 7.10), so that there is no apparent influence of smoking on the 'overnight recovery' in ventilatory capacity.

Influence of Productive Cough.-Only five subjects were considered to have a productive cough; Table 8 sets out the detailed statistical analysis. For four of

TABLE 8

MEAN CHANGES IN F.E.V.1.0 ACCORDING TO PRESENCE OR ABSENCE OF PRODUCTIVE COUGH UNDER OBSERVATION

\begin{tabular}{|c|c|c|c|c|c|}
\hline & $\overline{\mathbf{x}}$ & $\mathbf{n}$ & $\mathbf{s}$ & $\mathbf{t}$ & $\mathbf{P}$ \\
\hline $\begin{array}{l}\text { A - B } \\
\text { 1. Present } \\
\text { 2. Absent } \\
\text { 3. Comparison of } \\
1 \text { and } 2\end{array}$ & $\begin{array}{l}-0.227 \\
-0.142\end{array}$ & $\begin{array}{r}4 \\
41 \\
45\end{array}$ & $\begin{array}{l}0.205 \\
0.211\end{array}$ & $\begin{array}{l}3 \cdot 72 \\
4.25\end{array}$ & $\begin{array}{c}<0.05>0.025 \\
<0.001 \\
\text { n.s. }\end{array}$ \\
\hline $\begin{array}{l}\text { C - D } \\
\text { 4. Present } \\
\text { 5. Absent } \\
\text { 6. Comparison of } \\
4 \text { and } 5\end{array}$ & $\begin{array}{l}-0.154 \\
-0.124\end{array}$ & $\begin{array}{r}5 \\
43 \\
48\end{array}$ & $\begin{array}{l}0.135 \\
0.243\end{array}$ & $\begin{array}{l}2 \cdot 56 \\
3 \cdot 35\end{array}$ & $\begin{array}{c}<0.10>0.05 \\
<0.005>0.001 \\
\text { n.s. }\end{array}$ \\
\hline $\begin{array}{l}\text { A }- \text { C } \\
\text { 7. Present } \\
\text { 8. Absent }\end{array}$ & $\begin{array}{r}-0.036 \\
+0.030\end{array}$ & $\begin{array}{r}5 \\
41\end{array}$ & & & $\begin{array}{l}\text { n.s. } \\
\text { n.s. }\end{array}$ \\
\hline
\end{tabular}

these, the mean decreases for F.E.V.1.0 ${ }_{\cdot 1 \cdot 0}$ on Monday and on Friday were $-227 \mathrm{ml}$. and $-192 \mathrm{ml}$. respectively, with a mean decrease of $-190 \mathrm{ml}$. over the entire week, and a decrease in the initial values between Monday and Friday of $36 \mathrm{ml}$. These are larger decreases than were revealed in the series as a whole, but in a small group they do not differ statistically from the mean decreases in the remainder. The fifth man, who admitted to mild chest symptoms on Mondays, had an F.E.V.1.0 2.33 litres on Monday morning and 2.32 litres on both occasions on Friday; the Monday afternoon reading was one of those which was lost. Initial values on Monday and on Friday did not change significantly (Table 8.7, 8.8). There is therefore no conclusive evidence of an adverse effect of productive cough on the ventilatory response to exposure to cotton dust, but the prevalence of productive cough in this series is noted to be relatively low (see below).

Influence of History of Cough and Sputum.-A history of cough and sputum for more than three months in the year was obtained from nine men, all but one of whom smoked. The changes over both days, over the week and between the Monday and Friday mornings closely parallel those for the remainder of the series (Table 9), and this also

TABLE 9

MEAN CHANGES IN F.E.V ACCORDING TO HISTORY OF COUGH AND SPUTUM

\begin{tabular}{|c|c|c|c|c|c|}
\hline & $\overline{\mathbf{x}}$ & $\mathbf{n}$ & $\mathbf{s}$ & $\mathbf{t}$ & $\mathbf{P}$ \\
\hline $\begin{array}{l}\text { A - B } \\
\text { 1. Present } \\
\text { 2. Absent }\end{array}$ & $\begin{array}{l}-0.139 \\
-0.152\end{array}$ & $\begin{array}{r}8 \\
37\end{array}$ & $\begin{array}{l}0.136 \\
0.211\end{array}$ & $\begin{array}{l}2 \cdot 89 \\
4 \cdot 38\end{array}$ & $\begin{array}{l}<0.025>0.02 \\
<0.001\end{array}$ \\
\hline $\begin{array}{l}C-D \\
\text { 3. Present } \\
\text { 4. Absent }\end{array}$ & $\begin{array}{l}-0.146 \\
-0.123\end{array}$ & $\begin{array}{r}9 \\
39\end{array}$ & $\begin{array}{l}0.111 \\
0.255\end{array}$ & $\begin{array}{l}3.95 \\
3.01\end{array}$ & $\begin{array}{l}<0.005>0.001 \\
<0.005>0.001\end{array}$ \\
\hline
\end{tabular}

applies after exclusion of the female workers (none of whom admitted to cough and sputum). There is no evidence to suggest that a history of cough and sputum has any bearing on the observed changes.

Influence of Symptoms on Monday.-A history of mild tightness in the chest or of cough on most Mondays was obtained in seven men; in no instance was it suggested that this caused disability or even inconvenience. The mean decrease in F.E.V.1.0 during Monday in this group, although not significant, is larger than in those without symptoms on Monday (Table 10.1, 10.2) but not on Friday (Table $10.3,10.4)$; the differences are not significant. In any case, the decrease is largely confined to three of the subjects, the others (one defaulted) showing virtually no change. Two of the three showing a decrease suffered falls of 160 and $180 \mathrm{ml}$. between Monday and Friday mornings, the remainder showing no marked changes (Table 10.5, 10.6). The decrease for the group over the entire week was above the average for the remainder of the series without symptoms (Table 10.7, 10.8), but again the difference is not significant.

The influence of Monday symptoms is thus not well defined in this small number of men, but the results accord with an impression formed during the interviews that the symptoms were so mild as to 
TABle 10

MEAN CHANGES IN F.E.V.1.0 ACCORDING TO HISTORY OF MONDAY SYMPTOMS

\begin{tabular}{|c|c|c|c|c|c|}
\hline & $\overline{\mathbf{x}}$ & $\mathbf{n}$ & $\mathbf{s}$ & $\mathbf{t}$ & $\mathbf{P}$ \\
\hline $\begin{array}{l}\text { A - B } \\
\text { 1. Present } \\
\text { 2. Absent }\end{array}$ & $\begin{array}{l}-0.207 \\
-0.141\end{array}$ & $\begin{array}{r}6 \\
39\end{array}$ & $\begin{array}{l}0.218 \\
0.210\end{array}$ & $\begin{array}{l}2 \cdot 33 \\
4 \cdot 19\end{array}$ & $\begin{array}{l}<0.10>0.05 \\
<0.001\end{array}$ \\
\hline $\begin{array}{l}C-\text { Dresent } \\
\text { 4. Absent }\end{array}$ & $\begin{array}{l}-0.094 \\
-0.133\end{array}$ & $\begin{array}{r}7 \\
41\end{array}$ & $\begin{array}{l}0 \cdot 100 \\
0 \cdot 250\end{array}$ & $\begin{array}{l}2.49 \\
3.40\end{array}$ & $\begin{array}{l}<0.05>0.025 \\
<0.005>0.001\end{array}$ \\
\hline $\begin{array}{l}\text { A- C } \\
\text { 5. Present } \\
\text { 6. Absent }\end{array}$ & $\begin{array}{r}-0.049 \\
+0.035\end{array}$ & $\begin{array}{r}7 \\
39\end{array}$ & & & $\begin{array}{l}\text { n.s. } \\
\text { n.s. }\end{array}$ \\
\hline $\begin{array}{l}\text { A - D } \\
\text { 7. Present } \\
\text { 8. Absent }\end{array}$ & $\begin{array}{l}-0.143 \\
-0.102\end{array}$ & $\begin{array}{r}6 \\
40\end{array}$ & $\begin{array}{l}0.120 \\
0216\end{array}$ & $\begin{array}{l}3 \cdot 16 \\
2 \cdot 98\end{array}$ & $\begin{array}{l}<0.02>0.01 \\
<0.005>0.001\end{array}$ \\
\hline
\end{tabular}

make it doubtful whether the men reporting them formed a well defined group.

Influence of Duration of Employment in Cotton Mills.-Six subjects employed for less than a month showed a significant decrease in F.E.V.1.0 on Monday of $253 \mathrm{ml}$., whereas six employed for one to 12 months suffered a negligible decrease of $47 \mathrm{ml}$. Subjects employed for one to 10 years, 11 to 20 years, and 21 to 30 years had falls of 161,83 , and $106 \mathrm{ml}$.; for those in their first or second decades of employment these changes were significant. On Friday, decreases of over $100 \mathrm{ml}$. were found in all of these groups (except the second decade group, where the decrease averaged only $3 \mathrm{ml}$.), although the decrease was significant only in those employed between one and 10 years. The morning values in all groups were virtually identical, and no additional information was given by analysis in terms of change over the entire week (Table 11).

\section{TABLE 11}

MEAN CHANGES IN F.E.V.1.0 ACCORDING TO DURATION OF EMPLOYMENT

\begin{tabular}{l|c|r|c|c|c}
\hline & $\bar{x}$ & $\mathrm{n}$ & $\mathrm{s}$ & $\mathrm{t}$ & $\mathrm{P}$ \\
\hline $\mathbf{A}-\mathrm{B}$ 1. 1 month & -0.253 & 6 & 0.214 & 2.90 & $<0.05>0.025$ \\
2. 1-12 months & -0.047 & 6 & 0.097 & 1.21 & $<0.30>0.20$ \\
3. 1-10 years & -0.161 & 14 & 0.178 & 3.38 & $<0.005>0.001$ \\
4. 11-20 years & -0.083 & 8 & 0.053 & 4.43 & $<0.005>0.001$ \\
5. 21-30 years & -0.106 & 9 & 0.315 & 1.01 & $<0.40>0.30$ \\
\hline
\end{tabular}

There is therefore suggestive evidence that recent employees are more susceptible to the effects of exposure but no evidence in the series as a whole of any change in the pattern of reactivity over a week with increasing duration of employment (the patterns of change over a week are the subject of discussion below).
Influence of Isoprenaline Aerosol.-Isoprenaline by aerosol produced an increase in F.E.V.1.0 in all 15 subjects in whom it was measured, the mean increase being $119 \mathrm{ml}$. ( $P<0.001)$. These men had shown a mean decrease of $105 \mathrm{ml}$. over the week preceding the aerosol. The individual decreases were more than eliminated in nine subjects. In the remaining men, the residual decreases over the week after isoprenaline administration were less than $100 \mathrm{ml}$. in four cases and between 200 and $300 \mathrm{ml}$. in the other two. The latter two in fact complained of symptoms in the dust; two others with symptoms given isoprenaline had shown virtually no change in F.E.V.1.0 on exposure. Hence, although isoprenaline has its expected effect on the ventilatory capacity of the series as a whole, it does not necessarily follow that decreases over a week in men with symptoms are wholly reversible by this drug.

Relevance of Forced Expiratory Ratio.-No correlation $(r=-0.15)$ was found between the decreases in F.E.V $\cdot_{1 \cdot 0}$ on Monday and the initial F.E.V.1.0 or the forced expiratory ratio (F.E.R.). However, the 17 subjects with an F.E.R. of 0.80 to 0.89 showed a highly significant mean decrease in F.E.V.1.0 during Monday of $162 \mathrm{ml}$., whereas the mean decrease $(93 \mathrm{ml}$.) in the 15 subjects with ratios between 0.70 and 0.79 was not significant (Table 12.1, 12.2); the difference between the two groups is not significant. The mean decrease for the five subjects?

TABLE 12

MEAN CHANGES IN F.E.V.1.0 ACCORDING TO FORCED EXPIRATORY RATIO (F.E.V.1.0/V.C.)

\begin{tabular}{l|c|c|c|c|c}
\hline & $\bar{x}$ & n & s & t & P \\
\hline A - B 0.90 & & & & & \\
$1 .>0.223$ & 8 & 0.151 & 4.18 & $<0.005>0.001$ \\
2. $0.80-0.89$ & -0.162 & 17 & 0.166 & 4.02 & $<0.001$ \\
3. $0.70-0.79$ & -0.093 & 15 & 0.255 & 1.41 & $<0.20>0.10$ \\
$4 .<0.70$ & -0.180 & 5 & 0.307 & 1.31 & $<0.30>0.20$ \\
\hline
\end{tabular}

with an F.E.R. $<0.70$ was $180 \mathrm{ml}$. (range $-3 \mathrm{ml}$. to $-620 \mathrm{ml}$.), and for those with a ratio of 0.90 or above (eight subjects) the mean decrease was $223 \mathrm{ml}$. (range -20 to $-460 \mathrm{ml}$.), which is significant. Consideration of possible sex or age differences in F.E.R. does not account for these findings.

Behaviour of Forced Vital Capacity. - The apparent significance of the initial value for the ratio F.E.V.1.0/F.V.C. led us to examine the changes which occurred in the F.V.C. For the entire series, the mean decrease in F.V.C. during Monday was $85 \mathrm{ml}$. $(\mathrm{P}<0.01>0.005)$ compared with a decrease of $150 \mathrm{ml}$. in F.E.V.1.0. Within various subgroups, 
such as those with and without a productive cough, the mean decrease in F.V.C. remained consistently less than the decrease in F.E.V.1.0. When the series was divided on a basis of the F.E.R. into those with a ratio of 0.70 to 0.79 and those with a ratio of 0.80 to 0.89 , the mean decreases in F.V.C. of $108 \mathrm{ml}$. and $44 \mathrm{ml}$. respectively were not significant $(P<0.20$ $>0.10$ in both cases). These findings add nothing to the interpretation of the F.E.V.1.0 that presumably the F.E.R. on the average shows a slight decrease after exposure. Carey, Elwood, McAulay, Merrett, and Pemberton (1963) also found the analysis of F.V.C. less informative than the analysis of F.E.V.1.0 in their short-term studies.

\section{Discussion}

The finding that workers in the blowing, carding, and spinning preparation areas of a cotton mill almost uniformly show a decrease in ventilatory capacity during a working day is consistent with the data of McKerrow, McDermott, Gilson, and Schilling (1958) in mill B, and with the observation that non-byssinotic and byssinotic subjects experimentally exposed to cotton dust may show similar changes in pulmonary function (McKerrow, Roach, Gilson, and Schilling, 1962). No increased effect was observed in the afternoon compared with the morning shift, as noted by Bouhuys, Hartogensis, and Korfage (1963) in flax workers, perhaps because our subjects consistently worked the same shift. Seven of our subjects had symptoms of byssinosis-grade 1 in one case, in six barely sufficient to warrant classification as grade $\frac{1}{2}$ (Roach and Schilling, 1960), and sometimes related by the men themselves to their first cigarette at the lunch or tea break rather than to the dust. These subjects showed no significant differences in response from the series as a whole. We doubt whether the history accurately differentiates a specific 'byssinotic' group in our series, and therefore we are not prepared to conclude that byssinotic and non-byssinotic subjects behave in a similar way under Australian conditions; the slightly more marked changes in our 'byssinotics', even though not significantly different from the remainder, might be considered as more in keeping with those found by McKerrow et al. (1958) for their grade 1 byssinotic subjects. Our experience in several occupational surveys has been that the history of symptoms on exposure may be wittingly or unwittingly influenced by extraneous factors, so that prevalence rates based on the history alone may be either underestimated (Bouhuys, Van Duyn, and Van Lennep, 1961) or overestimated (especially where a hazard is suspected) (Gandevia and Ritchie, in preparation). The tentative sugges- tion (Roach and Schilling, 1960; McKerrow et al., 1962) that symptoms may be related to large particles (greater than $7 \mu$ ) and ventilatory changes to smaller particles could also explain a discrepancy between symptomatology and objective tests in special circumstances. However, taken at face value, our data indicate a lower prevalence of byssinosis (14\%) than is recorded by Batawi, Schilling, Valić, and Walford (1964) in Egypt, or by Schilling, Hughes, DingwallFordyce, and Gilson (1955) in Britain (even after allowance for differences in the age and duration of exposure), although close to later British and Dutch figures (Lammers, Schilling, and Walford, 1964). There is, however, no doubt of its lesser severity. Within the limitations of a single small survey, these findings support the view of industrial physicians that clinically significant or disabling byssinosis is uncommon in this country. In Victoria and New South Wales only one claim for workers' compensation (successful but disputed) is recorded to our knowledge, although claims could succeed on comparatively slender grounds, including the aggravation of preexisting or non-industrial bronchopulmonary disease.

It seems important to establish with certainty whether or not byssinotic and non-byssinotic subjects react on exposure in quantitatively or qualitatively different ways, in terms of ventilatory capacity, both over a working shift and a working week, and to study the factors involved in any differences between these groups. Without this information, changes in ventilatory capacity observed at work cannot be effectively used to substantiate the clinical diagnosis, nor, of course, can they serve as a basis for predicting potentially byssinotic subjects. A careful review of the published data, including our own, does not establish that these aims have been achieved in the cotton industry, even though considerable progress has been made in relating ventilatory capacity to the dust content of the air (Roach and Schilling, 1960; McKerrow et al., 1958; Batawi et al., 1964).* Although we believe that ventilatory capacity changes in byssinotic and non-byssinotic subjects have not been sufficiently defined within statistically reliable limits for unselected populations even for one working shift in the cotton industry, it is of greater interest to illustrate the point from an examination of the recorded patterns of reaction over a week in several industries in which 'byssinosis' occurs with varying frequency. In the nine published population surveys of this type in which a significant decrease in ventilatory capacity is observed on Monday, two subsequent patterns of reaction are manifest: (1) there is 'overnight' recovery (similar

\footnotetext{
* From this point of view, it is unfortunate that no suitable instrument for measuring dust concentrations was available to us, especially as we failed to demonstrate any relation to dustiness as judged by eye.
} 
initial or morning values on Monday and on a day late in the week) with a significant decrease on exposure during the 'end of week' day; (2) there is little or no 'overnight' recovery, a significant difference between the initial values for Monday and the 'end of week' day, and no significant fall during the latter day. These patterns are illustrated in Fig. 1, the first from the present study, and the second from our survey of jute workers.

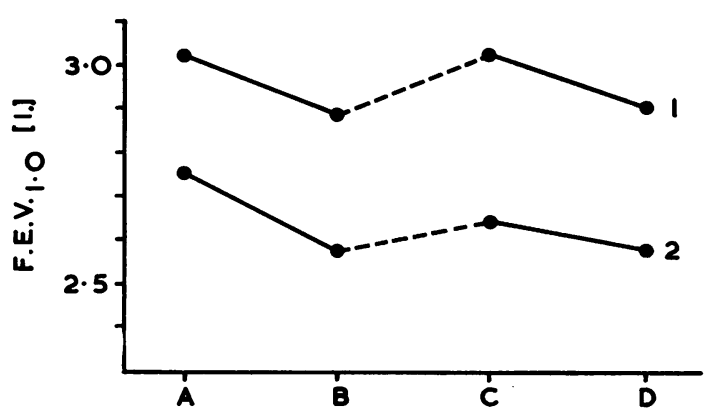

FIGURE 1.-Patterns of ventilatory capacity change over a working week.

(1) The first pattern described in the text (significant decrease during Monday $(A-B)$, 'overnight' recovery $(B-C)$, and significant decrease on Friday $(C-D))$; data from present study.

(2) Second pattern (significant decrease on Monday $(A-B)$, incomplete recovery 'overnight' $(B-C)$, the mean for Friday morning being significantly less than that for Monday morning, and no significant further decrease during Friday); data relate to jute workers with a productive cough (Gandevia and Milne,
1965).

Pattern 1 is recorded for selected cotton workers with grade II byssinosis (McKerrow et al., 1958), for flax workers with grade II byssinosis (Carey et al., 1963), and for non-byssinotic cotton workers in the present series (the order of magnitude of the changes beingless than in the byssinotics studied by McKerrow et al., 1962). Pattern 2 is recorded for flax workers, mostly with grade I byssinosis (Bouhuys et al., 1961), for smokers not deliberately exposed to dust in a flax mill (Carey et al., 1963), for cotton weavers, mostly with grade I byssinosis (Bouhuys, 1963), and for workers with a productive cough exposed to jute dust (Gandevia and Milne, 1965). Selected cotton workers with grade I byssinosis (McKerrow et al., 1958) show a marked tendency towards overnight recovery (relevant statistics are not quoted) and a significant decrease on Thursday, which is significantly less than on Monday; this and the afternoon shift of workers exposed to chemically retted flax studied by Bouhuys et al. (1963) may perhaps be regarded as variants of the second pattern. Our inconclusive data on subjects with grade $\frac{1}{2}$ byssinosis show a similar trend. Significant and comparable decreases in ventilatory capacity on both days as well as between the initial morning values appear surprisingly uncommon. The only fully analysed example known to us is for workers exposed to a chemical irritant (toluene di-isocyanate) (Gandevia, 1963).

These patterns seem to be real and not chance findings, in spite of the smallness of the groups, the various selection factors operative, the incomplete analysis of some of the data in respect of such factors as productive cough, smoking habit, dust concentrations, symptoms on exposure, and possible qualitative as well as quantitative differences in the biological activity of the dusts (Davenport and Paton, 1962). Nevertheless, it is not easy to see any general principles underlying this behaviour. It is odd, if not frankly paradoxical, that in the cotton industry progression from asymptomatic to grade I and ultimately grade II byssinosis should be associated with a change from the first to the second pattern, perhaps with a transient phase of tolerance (vide supra Results, Duration of Employment), and back to the first again, especially if at the same time an irreversible loss of ventilatory function is gradually being superimposed. It is interesting that the second pattern of reaction should be shared by nonbyssinotic jute workers with a productive cough, and by smokers, protected from exposure to flax dust as controls (but presumably possibly exposed to other dusts in some degree in the course of their work as joiner, bricklayer or fitter), as well as by cotton or flax workers with grade I byssinosis. Perhaps this implies a closer link between bronchitis and byssinosis than the African experience of Gilson, Stott, Hopwood, Roach, McKerrow, and Schilling (1962) would allow, and indeed a basic enough link to explain the disporportionately high prevalence of smoking in byssinotic flax workers noted by Carey et al. (1963). Only a prospective study can establish more clearly the relations of these patterns of reaction to fully developed byssinosis.

In spite of similar smoking habits, the prevalence of a productive cough under observation is lower in the cotton workers (five of 35 men) than in jute workers (13 of 46) of comparable age. The latter figure is more in accord with our experience in other surveys. In studies of workers with grain, phosphate rock (Gandevia and Ritchie, in preparation), and isocyanate (Gandevia, 1963), as well as jute, there has been evidence, usually statistically significant, of a greater reduction in ventilatory capacity on exposure in those with a productive cough; the present study is no exception. In this country, a productive cough is largely a function of smoking habit (O'Sullivan, Mackay, Ritchie, and Gandevia, unpublished data) so that trends towards greater decreases in smokers than in non-smokers are also 
found. Although this difference between smokers and non-smokers was reasonably well defined, qualitatively as well as quantitatively, in the jute workers, it is less remarkable, certainly over the whole week, in cotton workers, even though the overall average decreases in the cotton series are considerably more impressive than in the jute workers. These findings support the view that there may be an association between chronic bronchitis* and the development of disability on exposure to occupational hazards. On the other hand, the relatively low prevalence of productive cough and the comparatively 'average' behaviour of the smokers, in terms of ventilatory changes, suggest to us that there may have been some selection among the cotton employees. Except for the observation of McKerrow and Schilling (1961) in America that heavy smokers among cotton workers suffered a mean decrease in ventilatory capacity twice that of non-smokers or light smokers (the difference was not significant in a small series), we have found no comparable data in the literature on the relevance of smoking.

Further evidence in favour of a process of 'selfselection' follows from our finding of a significant decrease in F.E.V..$_{1 \cdot 0}$ in new employees (less than one month's employment) but no such decrease in those employed for longer periods up to a year. When shown these figures, the personnel officer recalled that many employees resigning within this period said that the dust affected their breathing or made them wheeze, and in fact over half the resignations in any one year occur within the first three months.

A curious difference between the jute and cotton workers is that in the former the greater and more significant decreases were found in those with the lower forced expiratory ratios, whereas the reverse was true of the cotton workers. We have no satisfactory explanation for this. Perhaps a process of selection is tending to exclude those with the lower ratios from the cotton industry. As the distributions of F.E.R. in the two series are very similar, this explanation presumably further requires that exposure to cotton dust has tended to reduce the F.E.R. from previously high levels with, at the same time, some reduction in reactivity to short-term exposure. In effect, it is thus postulated that we are seeing the natural history of 'byssinosis' at a subclinical level. This interesting view is not supported in another study of a group of men exposed on separate occasions to different dusts: in wheat dust, the more 'potent' dust under the conditions of the study, the decreases were greater in the F.E.R. range 0.80 to 0.89 , whereas on exposure to relatively inert tricalcium phosphate rock the decreases were greater

*Defined simply as persistent cough and sputum for more than three months of the year, for which no other cause is apparent. in those with an F.E.R. of 0.70 to 0.79 (Gandevia and Ritchie, in preparation). An alternative suggestion, that jute and phosphate rock are dusts merely irritant to those with some pre-existing airways obstruction, does not explain why the trend is reversed in those exposed to cotton or wheat. Different mechanisms producing the F.E.V.1.0 changes might be accompanied by different patterns of change in F.V.C., but in general our data suggest that F.E.V.1.0 and F.V.C. changes are consistent with one another.

This study establishes that cotton dust in an Australian mill is capable of producing decreases in ventilatory capacity over a day of the same order of magnitude as in Britain, and that under the conditions of the respective exposures it is considerably more potent in its effect than jute. If, provisionally, we accept the evidence that clinical or disabling byssinosis is less common in Australia than in Britain, it is important to seek the reasons. Two explanations, which are not mutually exclusive, may be offered. The first is that a factor of 'self-selection' is operative (evidence has been presented to support this view) and is more effective in Australia. Senior personnel, representing both management and employees, familiar with the cotton industry in both countries assure us that it has always been easier for workers in Melbourne and Sydney cotton mills to obtain a job in another industry and more common for them to seek one. Secondly, whatever factors are operative to produce the higher prevalence of disabling chronic bronchitis in Britain may be influencing the different prevalences of disabling byssinosis (Lammers et al., 1964).

We are indebted to Mrs. Heather Lovell, B.Sc., for technical and statistical aid, to Dr. G. B. Field and Miss Mary McNeil for other assistance, and to Mrs. Wendy Britten for patient secretarial help. A grant for apparatus was generously made available by the Post-Graduate Committee in Medicine, University of Sydney. One of us (J.M.) is indebted to the Chief Health Officer, Victorian Department of Health (Dr. K. Brennan) and the Chief Industrial Hygiene Officer (Dr. A. Christophers) for leave and financial assistance to carry out this work. The other wishes to express his appreciation of the help and encouragement offered over several years by Dr. John Gilson and his colleagues and by Dr. Charles Fletcher.

\section{REFERENCES}

Batawi, M. A. El, Schilling, R. S. F., Valić, F., and Walford, Joan (1964). Brit. J. industr. Med., $21,13$.

Bouhuys, A. (1963). Arch. environ. Hlth, 6, 465

-, Van Duyn, J., and Van Lennep, H. J. (1961). Ibid., 3. 499. Hartogensis, F., and Korfage, H. J. H. (1963). Brit. J. industr. Med., 20, 320.

Carey, G. C. R., Elwood, P. C., McAulay, I. R., Merrett, J. D., and Pemberton, J. (1963). Byssinosis in Flax Workers in Northern Ireland: Report to the Minister of Labour and National Ireland: Report to the Minister of Labour and National
Insurance, Government of Northern Ireland (roneoed typescript). 
Davenport, Anne, and Paton, W. D. M. (1962). Brit. J. industr. Med., $19,19$.

Gandevia, B. (1963), Ibid., 20, 204.

and Milne, J. (1965). Ibid., 22, 187.

Gilson, J. C., Stott, H., Hopwood, B. E. C., Roach, S. A., McKerrow, C. B., and Schilling, R.S. F. (1962). Ibid., $19,9$.

Lammers, B., Schilling, R. S. F., and Walford, Joan, with Meadows,

S., Roach, S. A., Van den Hoven van Genderen, D., Van der

Veen, Y. G., and Wood, C. H. (1964). Ibid., 21, 124.

Leading Article (1962). Brit. med. J., 2, 781 .
McKerrow, C. B., McDermott, M., Gilson, J. C., and Schilling, R. S. F. (1958). Brit. J. industr. Med., 15, 75 .

- Roach S. A. Gilson, J. C., and Schilling R. S. F. (1962) Ibid., 19, 1 .

- and Schilling, R. S. F. (1961). J. Amer. med. Ass., 177, 850.

Roach, S. A., and Schilling, R. S. F. (1960). Brit. J. industr. Med., 17,1 .

Schilling, R. S. F. (1956). Lancet, 2, 261 and 319.

Hughes, J. P. W., Dingwall-Fordyce, I., and Gilson, J. C. (1955). Brit. J. industr. Med., 12, 217.

\section{THE JULY (1965) ISSUE}

The July (1965) issue contains the following papers:-

Report and Recommendations of the Working Group on Asbestos and Cancer

Effects of Calcium Sodium Ethylenediaminetetra-Acetate on the Kinetics of Distribution and Excretion of

Lead in the Rat. N. Castellino and S. Aloj

Lead Exposure and the Derivation of Maximum Allowable Concentrations and Threshold Limit Values.

K. TsuchiYa and S. Harashima

Ventilatory Capacity on Exposure to Jute Dust and the Relevance of Productive Cough and Smoking to the

Response. B. Gandevia and J. MiLne

Study of Respiratory Symptoms and Ventilatory Capacities Among Rope Workers. D. F. Munt, S. Gauvain, J. WALFORD, and R. S. F. SCHILling

Respiratory Function and Symptoms in Rope Makers. C. B. MCKerrow, J. C. Gilson, R. S. F. SchiLling, and J. W. SKIDMORE

Experimental Investigation of the Effects of Direct Current Electric Shock on Respiration. A. L. ANGeLIS,

W. R. LEE, and S. ZOLEDZIOWSKI

Controlled Trial of Influenza Vaccine. P. B. Cook

Organo-Chlorine Insecticide Content of Human Adipose Tissue in South-Eastern England. J. RoBINson,

A. Richardson, C. G. Hunter, A. N. Crabtree, and H. J. Rees

Poisoning by Meta-Isosystox in Spraymen and in Accidentally Exposed Patients. M. R. HegazY

Phosphamidon Poisoning. S. Gitelson, J. T. Davidson, and A. Werczberger

Effects on the Coproporphyrin Test of Drugs Used in the Treatment of Parasitic Disease. F. Valić,

M. H. Noweir, and Z. SKurIĆ

Book Reviews

A number of copies are still available and may be obtained from the Publishing Manager, British Medical Association, Tavistock Square, W.C.1, price 18s. $6 d$. 